\title{
Real power loss diminution by rain drop optimization algorithm
}

Lenin Kanagasabai

Department of EEE, Prasad V. Potluri Siddhartha Institute of Technology, Kanuru, Vijayawada, Andhra Pradesh, India

\section{Article Info}

Article history:

Received Apr 29, 2020

Revised Mar 15, 2021

Accepted Apr 16, 2021

Keywords:

Optimal reactive power

Rain drop optimization

algorithm

Transmission loss

\begin{abstract}
In this work, the rain drop optimization (RDO) algorithm is projected to reduce power loss. Proceedings of rain drop have been imitated to model the RDO algorithm. The natural action of rain drop is flowing downwards from the peak and it may form small streams during the headway from the mountain or hill. As by gravitation principal rain drop flow as a stream as a river from the peak of mountains or hill then it reaches the sea as global optimum. Proposed rain drop optimization (RDO) algorithm evaluated in IEEE 30, bus test system. Power loss reduction, voltage deviation minimization, and voltage stability improvement have been achieved.
\end{abstract}

This is an open access article under the CC BY-SA license.

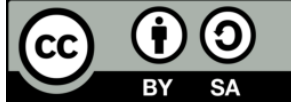

\section{Corresponding Author:}

Lenin Kanagasabai

Department of EEE

Prasad V. Potluri Siddhartha Institute of Technology

Kanuru, Vijayawada, Andhra Pradesh-520007, India

Email: gklenin@gmail.com

\section{INTRODUCTION}

Real power loss reduction is main objective of this work. Various methods conventional [1]-[6] and Evolutionary techniques [7]-[19] are applied to solve the problem. Rain drop optimization (RDO) Algorithm applied to reduce the power loss. Rain drop actions have been imitated to model the algorithm. Natural behavior of rain drop is flowing downwards form the peak and it will form small streams during the progression from the hill. With reference to the gravitation the raindrop flow as stream then as river from the peak of mountains or hill then finally it reaches the sea. Reaching the sea by passing many areas including valleys is global optimum. Raindrops are engendered in arbitrary mode in the initial iteration itself, then each rain drop will assign a neighborhood by itself then in arbitrary mode neighbor points are produced. Projected algorithm begins with arbitrarily engendered solution afterwards exploration has been done sequentially around the present point until end of the end criterion and also revision of the present value will be there throughout the procedure. Rain drop optimization (RDO) Algorithm evaluated in standard IEEE 30, bus test system. Voltage deviation and power minimization achieved along with voltage enhancement.

\section{PROBLEM FORMULATION}

Solving the optimal reactive power dispatch (ORPD) problem plays a significant role in the efficient operation and planning of the power system. The aim of solving the ORPD is to determine the best operating point of system for maximizing the voltage stability, minimizing the system loss and the voltage deviations. The best operating point includes the terminal voltages of the generators, taps of transformers and the injected reactive powers of the shunt compensators. The solution of the ORPD problem is formulated as an 
optimization problem applied for assigning set control parameters for a certain objective function, satisfying the operating constraints of the system.

Minimization $\tilde{\mathrm{F}}(\overline{\mathrm{x}}, \overline{\mathrm{y}})$

Subject to (2):

$$
\begin{aligned}
& E(\bar{x}, \bar{y})=0 \\
& I(\bar{x}, \bar{y})=0 \\
& x=\left[V_{1}, \ldots, V_{N_{g}} ; Q_{1}, \ldots, Q_{N_{c}} ; T_{1}, \ldots, T_{N_{T}}\right] \\
& y=\left[\mathrm{PG}_{\text {slack }} ; V_{1}, \ldots, V_{N_{L_{\text {Lod }}}} ; \mathrm{QG}_{1}, \ldots, \mathrm{QG}_{\mathrm{Ng}} ; \mathrm{SL}_{1}, \ldots, \mathrm{SL}_{\mathrm{N}_{\mathrm{T}}}\right]
\end{aligned}
$$

Fitness function $\left(\mathrm{F}_{1}\right)(6)$ is defined to diminish the power loss (MW).

$$
\mathrm{F}_{1}=\mathrm{P}_{\mathrm{Min}}=\operatorname{Min}\left[\sum_{\mathrm{m}}^{\mathrm{NTL}} \mathrm{G}_{\mathrm{m}}\left[\mathrm{V}_{\mathrm{i}}^{2}+\mathrm{V}_{\mathrm{j}}^{2}-2 * \mathrm{~V}_{\mathrm{i}} \mathrm{V}_{\mathrm{j}} \cos \emptyset_{\mathrm{ij}}\right]\right]
$$

Fitness function $\left(\mathrm{F}_{2}\right)$ minimization of Voltage deviation is (7).

$$
\mathrm{F}_{2}=\operatorname{Min}\left[\sum_{\mathrm{i}=1}^{\mathrm{N}_{\mathrm{LB}}}\left|\mathrm{V}_{\mathrm{Lk}}-\mathrm{V}_{\mathrm{Lk}}^{\text {desired }}\right|^{2}+\sum_{\mathrm{i}=1}^{\mathrm{Ng}}\left|\mathrm{Q}_{\mathrm{GK}}-\mathrm{Q}_{\mathrm{KG}}^{\mathrm{Lim}}\right|^{2}\right]
$$

Fitness function $\left(F_{3}\right)(8)$ voltage stability index (L-index) is $(9),(10),(11)$.

$$
\begin{aligned}
& \mathrm{F}_{3}=\operatorname{Min} \mathrm{L}_{\mathrm{Max}} \\
& \mathrm{L}_{\mathrm{Max}}=\operatorname{Max}\left[\mathrm{L}_{\mathrm{j}}\right] ; \mathrm{j}=1 ; \mathrm{N}_{\mathrm{LB}} \\
& \text { And }\left\{\begin{array}{c}
\mathrm{L}_{\mathrm{j}}=1-\sum_{\mathrm{i}=1}^{\mathrm{NPV}} \mathrm{F}_{\mathrm{ji}} \frac{\mathrm{V}_{\mathrm{i}}}{\mathrm{V}_{\mathrm{j}}} \\
\mathrm{F}_{\mathrm{ji}}=-\left[\mathrm{Y}_{1}\right]^{1}\left[\mathrm{Y}_{2}\right]
\end{array}\right. \\
& \mathrm{L}_{\text {Max }}=\operatorname{Max}\left[1-\left[\mathrm{Y}_{1}\right]^{-1}\left[\mathrm{Y}_{2}\right] \times \frac{\mathrm{V}_{\mathrm{i}}}{\mathrm{V}_{\mathrm{j}}}\right]
\end{aligned}
$$

Equality constraints:

$$
\begin{aligned}
& 0=P G_{i}-P D_{i}-V_{i} \sum_{j \in N_{B}} V_{j}\left[G_{i j} \cos \left[\emptyset_{i}-\emptyset_{j}\right]+B_{i j} \sin \left[\emptyset_{i}-\emptyset_{j}\right]\right] \\
& 0=Q G_{i}-Q D_{i}-V_{i} \sum_{j \in N_{B}} V_{j}\left[G_{i j} \sin \left[\emptyset_{i}-\emptyset_{j}\right]+B_{i j} \cos \left[\emptyset_{i}-\emptyset_{j}\right]\right]
\end{aligned}
$$

Inequality constraints:

$$
\begin{aligned}
& \mathrm{P}_{\text {gslack }}^{\min } \leq \mathrm{P}_{\text {gslack }} \leq \mathrm{P}_{\text {gslack }}^{\max } \\
& \mathrm{Q}_{\mathrm{gi}}^{\min } \leq \mathrm{Q}_{\mathrm{gi}} \leq \mathrm{Q}_{\mathrm{gi}}^{\max }, \mathrm{i} \in \mathrm{N}_{\mathrm{g}} \\
& \mathrm{VL}_{\mathrm{i}}^{\min } \leq \mathrm{VL}_{\mathrm{i}} \leq \mathrm{VL}_{\mathrm{i}}^{\max }, \mathrm{i} \in \mathrm{NL} \\
& \mathrm{T}_{\mathrm{i}}^{\min } \leq \mathrm{T}_{\mathrm{i}} \leq \mathrm{T}_{\mathrm{i}}^{\max }, \mathrm{i} \in \mathrm{N}_{\mathrm{T}}(17) \\
& \mathrm{Q}_{\mathrm{c}}^{\min } \leq \mathrm{Q}_{\mathrm{c}} \leq \mathrm{Q}_{\mathrm{C}}^{\max }, \mathrm{i} \in \mathrm{N}_{\mathrm{C}} \\
& \left|\mathrm{SL}_{\mathrm{i}}\right| \leq \mathrm{S}_{\mathrm{L}_{\mathrm{i}}}^{\max }, \mathrm{i} \in \mathrm{N}_{\mathrm{TL}}
\end{aligned}
$$




$$
\mathrm{VG}_{\mathrm{i}}^{\min } \leq \mathrm{VG}_{\mathrm{i}} \leq \mathrm{VG}_{\mathrm{i}}^{\max }, \mathrm{i} \in \mathrm{N}_{\mathrm{g}}
$$

Multi objective fitness is (21), (22), (23).

$$
\begin{aligned}
& \mathrm{MOF}=\mathrm{OF}_{1}+\mathrm{x}_{\mathrm{i}} \mathrm{OF}_{2}+\mathrm{yOF}_{3}=\mathrm{OF}_{1}+\left[\sum_{\mathrm{i}=1}^{\mathrm{NL}} \mathrm{x}_{\mathrm{v}}\left[\mathrm{VL}_{\mathrm{i}}-\mathrm{VL}_{\mathrm{i}}^{\mathrm{min}}\right]^{2}+\sum_{\mathrm{i}=1}^{\mathrm{NG}} \mathrm{x}_{\mathrm{g}}\left[\mathrm{QG}_{\mathrm{i}}-\mathrm{QG}_{\mathrm{i}}^{\mathrm{min}}\right]^{2}\right]+\mathrm{x}_{\mathrm{f}} \mathrm{OF}_{3} \\
& \mathrm{VL}_{\mathrm{i}}^{\min }=\left\{\begin{array}{l}
\mathrm{VL}_{\mathrm{i}}^{\max }, \mathrm{VL}_{\mathrm{i}}>\mathrm{VL}_{\mathrm{i}}^{\max } \\
\mathrm{VL}_{\mathrm{i}}^{\min }, \mathrm{VL}_{\mathrm{i}}<\mathrm{VL}_{\mathrm{i}}^{\min }
\end{array}\right. \\
& Q G_{i}^{\text {min }}=\left\{\begin{array}{c}
Q G_{i}^{\max }, Q G_{i}>Q G_{i}^{\max } \\
Q G_{i}^{\text {min }}, Q G_{i}<Q G_{i}^{\text {min }}
\end{array}\right.
\end{aligned}
$$

\section{RAIN DROP OPTIMIZATION ALGORITHM}

Natural behavior of rain drop is flowing downwards form the peak and it will form small streams during the progression from the hill [20]. In the projected algorithm rain drop will be a particle in the population, and it has been described as (24),

$$
D P^{i}=\left[Y_{i, 1}, Y_{i, 2}, Y_{i, 3}, \ldots, Y_{i, k}, \ldots, Y_{i, n}\right] i \in\{1,2,3, \ldots, m\}
$$

$\mathrm{DP}^{\mathrm{i}}$ symbolize rain drop, number of variables indicated by " $\mathrm{n}$ " and $\mathrm{Y}_{\mathrm{i}, \mathrm{k}}$ indicate the $\mathrm{k}^{\text {th }}$ variable in the problem, size of the population is defined by " $\mathrm{m}$ ". $\mathrm{DP}$ " has been assumed as a vector or point in the " $\mathrm{N}$ " dimensional axis and through uniform distribution it has been engendered as function with constraints as (25).

$$
\mathrm{Y}_{\mathrm{i}, \mathrm{k}}=\text { uniform distribution function (UDF). ( } \text { Lower }_{\mathrm{k}}, \mathrm{Upper}_{\mathrm{k}} \text { ) }
$$

With radius " $\mathrm{r}$ " around the point of Rain Drop (RD) in the " $\mathrm{N}$ " dimensional axis with respect to the neighborhood value the change in Rain Drop (RD) value will be modernized. A Rain Drop (RD) "i" which possess a neighbor point “ $\mathrm{j}$ ” is indicated by $\mathrm{NHP}_{\mathrm{j}}^{\mathrm{i}}$ as (26) and (27).

$$
\begin{aligned}
& \|\left(\mathrm{RD}^{\mathrm{i}}-\mathrm{NHP}_{\mathrm{j}}^{\mathrm{i}}\right) \text {. unit vector } \mathrm{k}\|\leq\| \operatorname{radius}(\mathrm{r}) \text {. unit vector }{ }_{\mathrm{k}} \| \\
& \operatorname{raduis}(\mathrm{r})=\text { raduis }_{\text {initial }} \times \mathrm{f}(\text { iteration })
\end{aligned}
$$

Naturally the dominant or main (M) neighbor point $\mathrm{NHP}_{\mathrm{M}}^{\mathrm{i}}$ satisfy amongst of all rain drop $\mathrm{RD}^{\mathrm{i}}$ and by objective function (F) the rain drop and neighbor point values are obtained by (28) and (29).

$$
\begin{aligned}
& \mathrm{F}\left(\mathrm{NHP}_{\mathrm{M}}^{\mathrm{i}}\right)<F\left(\mathrm{RD}^{\mathrm{i}}\right) \\
& \mathrm{F}\left(\mathrm{NHP}_{\mathrm{M}}^{\mathrm{i}}\right)<F\left(\mathrm{NHP}_{\mathrm{j}}^{\mathrm{i}}\right)
\end{aligned}
$$

No main point for a single rain drop $\mathrm{RD}^{\mathrm{i}}$ then predominantly in the position of stationary. Then the rain drop has been take out of this situation through a procedure of explosion is defined by (30).

$$
\mathrm{NHP}_{\text {exploration }}=\text { neighbor point } \times \text { explosion base } \times \text { explosion counter }
$$

The ranking of the rain drops in iteration's is given by (31) and (32).

$$
\begin{aligned}
& D 1_{t}^{i}=F\left(R D^{i}\right) \mid a t t^{t h} \text { iteration }-F\left(R D^{i}\right) \mid \text { at } 1^{\text {st }} \text { iteration } \\
& D 2_{t}^{i}=F\left(R D^{i}\right) \mid a t t^{t h} \text { iteration } \\
& \text { order }\left(D 1_{t}^{i}\right) \text {, order }\left(D 2_{t}^{i}\right) \text {; are orders at iteration } t \\
& \omega_{1}, \omega_{2} ; \text { are weight cofficients and ranking } t_{t}^{i} \text { is rank of rain drop } R D^{i}
\end{aligned}
$$

Raindrops are engendered in arbitrary mode in the initial iteration itself, then each rain drop will assign a neighborhood by itself then in arbitrary mode neighbor points are produced. Throughout the procedure of the optimization the neighbor point will be within in the exploration space limits and if any engendered beyond the exploration space limit, then it has been modernized by (34) and (35). 


$$
\begin{aligned}
& \operatorname{if}\left(\mathrm{NHP}_{\mathrm{j}}^{\mathrm{i}}\right)_{\mathrm{k}}<\operatorname{Lower}_{\mathrm{k}} \text { then }\left(\mathrm{NHP}_{\mathrm{j}}^{\mathrm{i}}\right)_{\mathrm{k}}=\operatorname{Lower}_{\mathrm{k}} \\
& \operatorname{if}\left(\mathrm{NHP}_{\mathrm{j}}^{\mathrm{i}}\right)_{\mathrm{k}}<\operatorname{Upper}_{\mathrm{k}} \operatorname{then}\left(\mathrm{NHP}_{\mathrm{j}}^{\mathrm{i}}\right)_{\mathrm{k}}=\operatorname{Upperr}_{\mathrm{k}}
\end{aligned}
$$

Subsequently for each rain drop and its neighbor points cost function will be computed then the comparison of values between rain drop and neighbor point will be done when there is dominant or main neighbor point found then the rain drop move towards to that point by altering its position.

- Begin

- Parameters values are engendered

- Fix each rain drop value as active

- Rain drop's initial population produced

- Iteration $=1$

- Drop number $=1$

- Explosion counter $=0$

- Is rain drop is active? if yes got to next step or else go to step "o"

- Engender the neighbor points

- Rain drop and neighbor point cost function value computed

- Change of rain drop position when a dominant neighbor point has been found then Explosion counter $=0$ then go to step "n"

- Otherwise, exploration process will be applied

- Fix the rain drop as live

- Swap the rain drop with dominant neighbor point

- Drop number +1

- Is drop number $<=$ number of population? If yes go to step "g"

- Otherwise, iteration +1

- Even after applying the exploration process no neighbor point found means then that particular rain drop is marked as motionless

- After creation of the worth order list then lower order value rain drops are marked as motionless

- Any live or active rain drop found; Itertaion $<=$ maximum itertaion

- If yes go step "f"

- Otherwise go to next step "w"

- For all rain drops the cost function value will be computed

- Discover the rain drop which possess the minimum cost functional value

- Then optimal solution is the cost and raindrop position

- End

\section{SIMULATION RESULTS}

Projected rain drop optimization (RDO) algorithm evaluated in standard IEEE 30 bus system [21]. Active and reactive power consumption is 2.8340 and 1.2620 per unit in 100 MVA base. Table 1 and Table 2 show the parameters [21]; then Table 3 to Table 6 show the comparison results. Figures 1-4 give the graphical comparison.

Table 1. Variables

\begin{tabular}{cccc}
\hline System [21] & Variables & Minimum (PU) & Maximum $(\mathrm{PU})$ \\
\hline & $\mathrm{VG}$ & 0.950 & 1.10 \\
& $\mathrm{Tt}$ & 0.90 & 1.10 \\
& $\mathrm{VAR}$ & 0.0 & 5.0 \\
\hline
\end{tabular}

Table 2. System parameters

\begin{tabular}{lc}
\hline Description [21] & IEEE 30 bus \\
\hline NB & 30 \\
NG & 6 \\
NT & 4 \\
NQ & 9 \\
NE & 41 \\
Power loss & 5.660 \\
Base casee for VD (Per Uit) & 0.582170 \\
\hline
\end{tabular}


Table 3. Power loss comparison with different metaheuristic algorithms

\begin{tabular}{lcccc}
\hline & DE [22] & GSA [23] & APO-PSO [24] & RDO \\
\hline Power Loss (MW) & 4.555 & 4.5143 & 4.398 & 0.940 \\
Voltage. D (PU) & 1.9589 & 0.87522 & 1.047 & 4.226 \\
L-index (PU) & 0.55130 & 0.141090 & 0.12670 & 1.044 \\
\hline
\end{tabular}

Table 4. Comparison with reference to voltage stability improvement

\begin{tabular}{lcccc}
\hline & DE [22] & GSA [23] & APO-PSO [24] & RDO \\
\hline Power loss (MW) & 6.4755 & 6.9117 & 5.698 & 5.429 \\
Volatge D (PU) & 0.0911 & 0.0676 & 0.087 & 0.083 \\
L-index (PU) & 0.143520 & 0.13490 & 0.13770 & 0.1314 \\
\hline
\end{tabular}

Table 5. Comparison with reference to voltage deviation minimization

\begin{tabular}{lcccc}
\hline & DE [22] & GSA [23] & APO-PSO [24] & RDO \\
\hline Power loss (MW) & 7.0733 & 4.9752 & 4.478 & 4.249 \\
Volatge. D (PU) & 1.419 & 0.21579 & 1.8579 & 1.8205 \\
L-index (PU) & 0.12460 & 0.136840 & 0.12270 & 0.1173 \\
\hline
\end{tabular}

Table 6. Comparison of values with reference to multi objective formulation

\begin{tabular}{lcc}
\hline & APO-PSO [24] & RDO \\
\hline Power Loss (MW) & 4.842 & 4.738 \\
Volatge. D (PU) & 1.009 & 1.003 \\
L-index (PU) & 0.1192 & 0.1184 \\
\hline
\end{tabular}

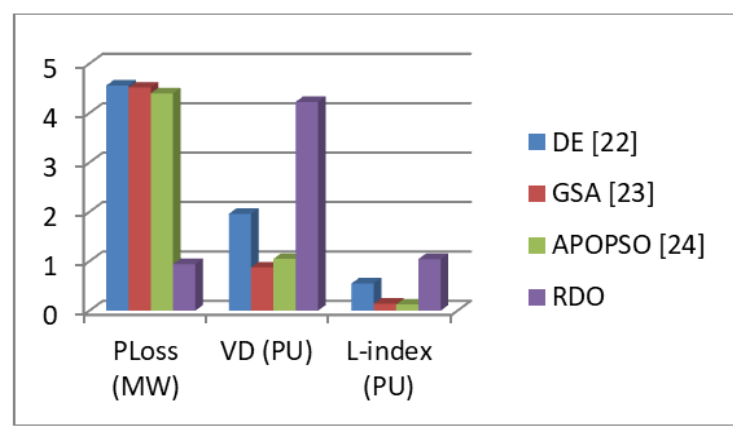

Figure 1. Comparison of power loss

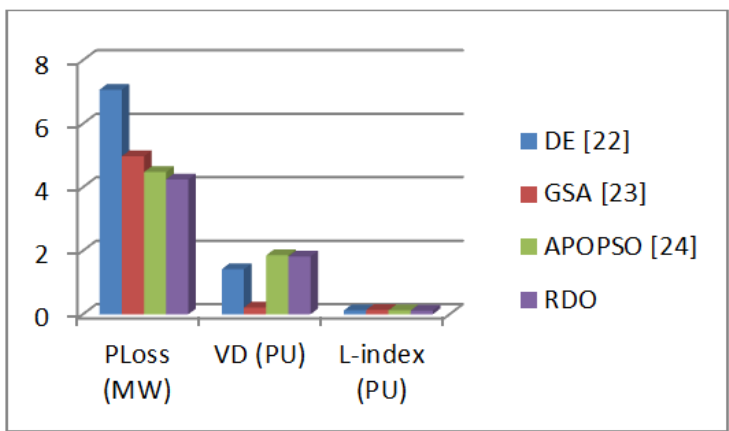

Figure 3. Comparison of loss with reference to VDM

Figure 4. Comparison of loss with reference to MOF

\section{CONCLUSION}

In this work optimal reactive power dispatch problem has been successfully solved by rain drop optimization (RDO) algorithm. Projected algorithm begins with arbitrarily engendered solution afterwards exploration has been done sequentially around the present point until end of the end criterion and also revision of the present value will be there throughout the procedure. Throughout the procedure of the 
optimization the neighbor point will be within in the exploration space limits and if any engendered beyond the exploration space limit, then it has been modernized. Rain drop optimization (RDO) algorithm evaluated in IEEE 30, bus test system. Voltage stability enhanced; power loss reduced with voltage deviation minimization.

\section{REFERENCES}

[1] K. Y. Lee, Y. M. Park, J. L. Ortiz, "Fuel-cost minimisation for both real and reactive-power dispatches," Proceedings Generation, Transmission and Distribution Conference, vol. 131, no. 3, pp. 85-93, 1984. [Online]. Available: https://digital-library.theiet.org/content/journals/10.1049/ip-c.1984.0012.

[2] O.Alsac, and B. Scott, "Optimal load flow with steady state security," IEEE Transaction. PAS -1973, pp. 745-751.

[3] K. Aoki, A. Nishikori, R. Yokoyama, "Constrained Load Flow Using Recursive Quadratic Programming," in IEEE Transactions on Power Systems, vol. 2, no. 1, pp. 8-16, Feb. 1987. [Online]. Available: https://ieeexplore.iee.org/abstract/document/4335064.

[4] D. S. Kirschen, H. P. Van Meeteren, "MW/voltage control in a linear programming based optimal power flow," in IEEE Transactions on Power Systems, vol. 3, no. 2, pp. 481-489, May 1988. [Online]. Available: https://ieeexplore.iee.org/abstract/document/192899.

[5] W. -. E. Liu, A. D. Papalexopoulos, W. F. Tinney, "Discrete shunt controls in a Newton optimal power flow," in IEEE Transactions on Power Systems, vol. 7, no. 4, pp. 1509-1518, Nov. 1992. [Online]. Available: https://ieeexplore.ieee.org/abstract/document/207375.

[6] V. H. Quintana, M. Santos-Nieto, "Reactive-power dispatch by successive quadratic programming," in IEEE Transactions on Energy Conversion, vol. 4, no. 3, pp. 425-435, Sept. 1989. [Online]. Available: https://ieeexplore.ieee.org/abstract/document/43245.

[7] V. de Sousa, E. Baptista, G. da Costa, "Optimal reactive power flow via the modified barrier Lagrangian function approach," Electric Power Systems Research, vol. 84, no. 1, pp. 159-164, 2012. [Online]. Available: https://www.sciencedirect.com/science/article/abs/pii/S0378779611002677.

[8] Uğur Arifoğlu, Faruk Yalçin, "System Constrained Active Power Loss Minimization in Practical Multi-terminal HVDC Systems through GA," Sakarya University Journal of Science, vol. 22, no. 4, pp. 1163-1173, 2018. [Online]. Available: http://www.saujs.sakarya.edu.tr/en/download/article-file/486207.

[9] S. Kamel, S. Abdel-Fatah, M. Ebeed, J. Yu, K. Xie, C. Zhao, "Solving Optimal Reactive Power Dispatch Problem Considering Load Uncertainty," 2019 IEEE Innovative Smart Grid Technologies - Asia (ISGT Asia), Chengdu, China, 2019, pp. 1335-1340.

[10] Biplab Bhattacharyya, Nihar Karmakar, "Optimal Reactive Power Management Problem: A Solution Using Evolutionary Algorithms,” IETE Technical Review, vol. 37, no. 5, pp. 540-548, 2019. [Online]. Available: DOI: 10.1080/02564602.2019.1675541.

[11] Ram Kishan Mahate, Himmat Singh, "Multi-Objective Optimal Reactive Power Dispatch Using Differential Evolution," International Journal of Engineering Technologies and Management Research, vol. 6, no. 2, pp. 27-38, 2019. [Online]. Available: https://doi.org/10.29121/ijetmr.v6.i2.2019.353.

[12] Nguyen, Thang Trung, Vo, Dieu Ngoc, "Improved social spider optimization algorithm for optimal reactive power dispatch problem with different objectives" Neural Computing and Applications, vol. 32, pp. 5919-5950, 2020. [Online]. Available: https://doi.org/10.1007/s00521-019-04073-4.

[13] S. Yang, W. Wang, C. Liu, Y. Huang, "Optimal reactive power dispatch of wind power plant cluster considering static voltage stability for low-carbon power system," in Journal of Modern Power Systems and Clean Energy, vol. 3, no. 1, pp. 114-122, March 2015. [Online]. Available: https://doi.org/10.1007/s40565-014-0091-x.

[14] S. Emiroglu, Y. Uyaroglu, G. Ozdemir, "Distributed Reactive Power Control based Conservation Voltage Reduction in Active Distribution Systems," Advances in Electrical and Computer Engineering, vol. 17, no.4, pp. 99-106, 2017. [Online]. Available: doi:10.4316/AECE.2017.04012.

[15] Mojtaba Ghasemi, Mahdi Taghizadeh, Sahand Ghavidel, Jamshid Aghaei, Abbas Abbasian, "Solving optimal reactive power dispatch problem using a novel teaching-learning-based optimization algorithm," Engineering Applications of Artificial Intelligence, vol. 39, pp. 100-108, 2015. [Online]. Available: https://www.sciencedirect.com/science/article/abs/pii/S0952197614002930.

[16] Wei, Yan-Ling, Nguyen, Thang Trung, Vo, Dieu Ngoc, Van Tran, Hai, Van Dai, Le, "Optimal Dispatch of Reactive Power Using Modified Stochastic Fractal Search Algorithm," Complexity, Hindwai, vol. 2019, ID. 4670820, pp. 1076-2787, 2019. [Online]. Available: https://doi.org/10.1155/2019/4670820.

[17] A. Padilha-Feltrin, D. A. Quijano Rodezno, J. R. S. Mantovani, "Volt-VAR Multiobjective Optimization to PeakLoad Relief and Energy Efficiency in Distribution Networks," in IEEE Transactions on Power Delivery, vol. 30, no. 2, pp. 618-626, April 2015. [Online]. Available: https://ieeexplore.ieee.org/abstract/document/6866925

[18] I. Khan, Z. Li, Y. Xu, W. Gu, "Distributed control algorithm for optimal reactive power control in power grids," International Journal of Electrical Power \& Energy Systems, vol. 83, pp. 505-513, Dec. 2016. [Online]. Available: https://www.sciencedirect.com/science/article/abs/pii/S0142061516306366.

[19] A. Castillo, P. Lipka, J. Watson, S. S. Oren, R. P. O'Neill, "A successive linear programming approach to solving the iv-acopf," in IEEE Transactions on Power Systems, vol. 31, no. 4, pp. 2752-2763, July 2016. [Online]. Available: https://ieeexplore.ieee.org/abstract/document/7299702. 
[20] H. Shah-Hosseini, "The intelligent water drops algorithm: a nature-inspiredswarm-based optimization algorithm," International Journal of Bio-Inspired Computation, vol. 1, no. 1-2, pp. 71-79, 2009. [Online]. Available: https://doi.org/10.1504/IJBIC.2009.022775.

[21] Illinois Center for a Smarter Electric Grid (ICSEG), [Online]. Available: https://icseg.iti.illinois.edu/ieee-30bussystem/ (accessed on 25 February 2019).

[22] El Ela A. A, Abido M. A, Spea, S. R, "Differential evolution algorithm for optimal reactive power dispatch," Electric Power Systems Research, vol. 81, no. 2, pp. 458-464, 2011. [Online]. Available: https://www.sciencedirect.com/science/article/abs/pii/S0378779610002385.

[23] Duman. S, Sönmez. Y, Güvenç. U, Yörükeren. N, "Optimal reactive power dispatch using a gravitational search algorithm," IET Generation Transmission, \& Distribution, vol. 6, no. 6, pp. 563-567, 2012.

[24] Aljohani T. M, Ebrahim A. F, Mohammed O, "Single and Multiobjective Optimal Reactive Power Dispatch Based on Hybrid Artificial Physics-Particle Swarm Optimization," Energies, vol. 12, no. 12, pp. 1-24, 2019. [Online]. Available: https://doi.org/10.3390/en12122333.

\section{BIOGRAPHY OF AUTHOR}

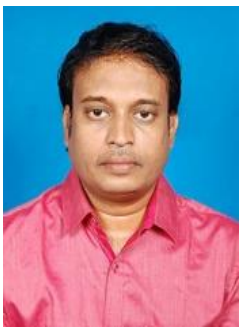

Lenin Kanagasabai has received his B.E., Degree in Electrical and Electronics Engineering from University of Madras, M.E., Degree in Power Systems from Annamalai University and completed $\mathrm{PhD}$ in Electrical Engineering from Jawaharlal Nehru Technological University Hyderabad, India. He published more than 300 international journal research papers and presently working as Professor in Prasad V. Potluri Siddhartha Institute of Technology, Kanuru, Vijayawada, Andhra Pradesh -520007. 